OPEN ACCESS

Edited by:

Marc Pallardy,

Université Paris-Sud, France

Reviewed by:

Muriel Pichavant,

INSERM U1019 Centre d'Infection et Immunité de Lille (CIIL), France Perrine Martin,

Université du Littoral Côte d'Opale, France

*Correspondence:

Carolyn J. Baglole carolyn.baglole@mcgill.ca Hussein Traboulsi

hussein.traboulsi@mail.mcgill.ca

Specialty section:

This article was submitted to Immunotoxicology,

a section of the journal

Frontiers in Toxicology

Received: 14 January 2021 Accepted: 07 June 2021 Published: 06 July 2021

Citation: Guerrina N, Traboulsi H, Eidelman DH and Baglole CJ (2021) The Aryl Hydrocarbon Receptor Suppresses Chronic Smoke-Induced Pulmonary Inflammation

Front. Toxicol. 3:653569. doi: 10.3389/ftox.2021.653569

\section{The Aryl Hydrocarbon Receptor Suppresses Chronic Smoke-Induced Pulmonary Inflammation}

\author{
Necola Guerrina ${ }^{1}$, Hussein Traboulsi ${ }^{1,2 *}$, David H. Eidelman ${ }^{2}$ and Carolyn J. Baglole ${ }^{1,2,3,4 *}$ \\ ${ }^{1}$ Research Institute of the McGill University Health Centre, Montreal, QC, Canada, ${ }^{2}$ Department of Medicine, McGill \\ University, Montreal, QC, Canada, ${ }^{3}$ Deaprtment of Pathology, McGill University, Montreal, QC, Canada, ${ }^{4}$ Department of \\ Pharmacology and Therapeutics, McGill University, Montreal, QC, Canada
}

The aryl hydrocarbon receptor (AhR) is a ligand-activated transcription factor expressed in the lungs that is activated by numerous xenobiotic, endogenous and dietary ligands. Although historically the AhR is known for mediating the deleterious response to the environmental pollutant dioxin, emerging evidence supports a prominent role for the AhR in numerous biological process including inflammation. We have shown that the AhR suppresses pulmonary neutrophilia in response to acute cigarette smoke exposure. Whether the AhR can also prevent lung inflammation from chronic smoke exposure is not known but highly relevant, given that people smoke for decades. Using our preclinical smoke model, we report that exposure to chronic cigarette smoke for 8-weeks or 4 months significantly increased pulmonary inflammation, the response of which was greater in $\mathrm{Ahr}^{-/-}$mice. Notably, there was an increased number of multinucleated giant cells (MNGCs) in smoke-exposed $\mathrm{Ahr}^{-/-}$mice without a change in cytokine levels. These data support a protective role for the AhR against the deleterious effects of cigarette smoke, warranting continued investigation into its therapeutic potential for chronic lung diseases.

Keywords: aryl hydrocarbon receptor, cigarette smoke, inflammation, lungs, multinucleated (foreign body) giant cell

\section{INTRODUCTION}

The aryl hydrocarbon receptor (AhR) is a transcription factor that is activated in response a multitude of low molecular weight compounds of both exogenous and endogenous origins; these include dioxins, polycyclic aromatic hydrocarbons (PAHs), plant polyphenols and tryptophan metabolites (Abel and Haarmann-Stemmann, 2010; Quintana, 2013). These bind to the ligandbinding domain located on the amino terminal of the cytoplasmic AhR. Upon entering the nucleus, the AhR dissociates from its chaperone proteins prior to heterodimerization with the aryl hydrocarbon receptor nuclear translocator (ARNT). This AhR-ARNT complex then binds to the xenobiotic response element in the promoter region of AhR target genes, the prototypical of which is cytochrome P450 (CYP) CYP1A1 (Nukaya et al., 2009).

Historically, the AhR is best-known for its ability to mediate the deleterious effects of the man-made toxicant 2,3,7,8-tetrachlorodibenzo-p-dioxin (TCDD; dioxin) (Bock, 1994; FernandezSalguero et al., 1996; Mimura et al., 1997). However, the AhR is evolutionarily conserved amongst multicellular organisms (Williams et al., 2014) and is highly expressed in the skin, gut, liver and lungs (Esser and Rannug, 2015). The lungs are continuously exposed to the external 
environment and are particularly sensitive to environmental toxicants, including those derived from air pollution (ambient, biomass) and cigarette smoke. Cigarette smoke is also a leading cause of preventable death and is the main risk factor for the development of lung cancer and chronic obstructive pulmonary disease (COPD). The pathogenesis of these diseases is typified by chronic inflammation, initiated and perpetuated by inhalation of cigarette smoke. Cigarette smoke is a complex mixture that contains chemicals that activate the AhR including the $\mathrm{PAH}$ benzo[a]pyrene $(\mathrm{B}[a] \mathrm{P})$. However, the $\mathrm{AhR}$ has emerged as a critical component of immunity, dampening the severity of diseases associated with chronic inflammation such as rheumatoid arthritis (Rosser et al., 2020; Nehmar et al., 2021), inflammatory bowel disease (Riemschneider et al., 2021), asthma (Chang et al., 2020), periodontitis (Huang et al., 2019), psoriasis (Di Meglio et al., 2014) and multiple sclerosis (Abdullah et al., 2019). We have previously shown that the AhR attenuates pulmonary neutrophilia in response to acute and sub-chronic cigarette smoke exposure (Thatcher et al., 2007; de Souza et al., 2014; Rico de Souza et al., 2021) and prevents the development of a COPD-like phenotype (Guerrina et al., 2021). However, it remains unknown whether the $\mathrm{AhR}$ can reduce inflammation caused by chronic cigarette smoke exposure, findings that are relevant given that people who develop COPD often smoke for decades. Therefore, we utilized our preclinical cigarette smoke model to study whether the AhR protects against chronic smoke-induced pulmonary inflammation. This work enhances our understanding of the AhR in protecting against the harmful effects of long-term cigarette smoking, which still claims the lives of millions of people each year.

\section{METHODS}

\section{Animals}

Ahr-knockout $\left(A h r^{-/-}\right)$C57BL/6 mice were obtained from Jackson Laboratory (Strain B6.129-Ahr ${ }^{\mathrm{tm} 1} / \mathrm{J}$; Bar Harbor, ME). Ahr heterozygous C57BL/6 mice $\left(A h r^{+/-}\right)$were bred in house and maintained on an ad libitum diet. $A h r^{+/+}$or $A h r^{+/-}$mice do not exhibit any difference in the ability to be activated by AhR ligands or cigarette smoke and are used interchangeably as AhRexpressing mice (Thatcher et al., 2007; Baglole et al., 2008; Zago et al., 2013; de Souza et al., 2014), rendering mice of the $\mathrm{Ahr}+/-$ genotype as littermate controls.

\section{Preclinical Cigarette Smoke Model}

Age and gender-matched $A h r^{-/-}$and $A h r^{+/-}$mice were exposed to cigarette smoke using a whole-body exposure system (InExpose; SCIREQ Inc., Montreal, Canada) for up to 4 months as previously described (Thatcher et al., 2007; Zago et al., 2013; de Souza et al., 2014). Mice were between 8 and 12 weeks at the start of the experiments, corresponding to $\sim 21$ years in humans (Dutta and Sengupta, 2016). Male mice were used for the 8 -week experiments (4-5 mice per group) and both male and female mice for the 4-month experiment (9-11 mice per group). Considering the lifespan between mice and humans, this corresponds to people who smoke for $\sim 6-12$ years (Dutta and Sengupta, 2016). All animal procedures were approved by the
McGill University Animal Care Committee (Protocol Number: 5933) and were carried out in accordance with the Canadian Council on Animal Care.

\section{Tissue Harvest and Bronchoalveolar Lavage (BAL) Collection}

Following the last exposure, mice were anesthetized with Avertin (2,2,2-tribromoethanol, $250 \mathrm{mg} / \mathrm{kg}$ ip; Sigma-Aldrich, St Louis, MO) and sacrificed by exsanguination. The lungs were removed and lavaged twice with $0.5 \mathrm{ml}$ of PBS. After the bronchoalveolar lavage (BAL) fluid was centrifuged, the supernatant was removed, and the BAL cell pellets were resuspended in PBS. Total cell counts were determined using a hemocytometer. Differential cell counts were performed after cytospin slide preparation (Thermo Shandon, Pittsburgh, PA) following staining with Hema-Gurr Stain (Merck, Darmstadt, Germany).

\section{Detection of Cytokine Levels}

BAL fluid was collected as described above and stored at $-80^{\circ} \mathrm{C}$ until used. BAL cytokine levels were evaluated using Luminex ${ }^{\circledR}$ technology (Milliplex xMAP, Millipore, Billerica, MA) for the 8 -week exposure or were performed by Eve Technologies (Calgary $\mathrm{AB})$.

\section{Statistical Analysis}

Statistical analysis was performed using Prism 6-1 (La Jolla, $\mathrm{CA})$. Statistical differences between group mean values were determined by 2-way analysis of variance (ANOVA) followed by the Neuman-Keuls multiple comparisons test unless otherwise indicated. In all cases, a $p<0.05$ is considered statistically significant.

\section{RESULTS}

\section{The AhR Attenuates Chronic Cigarette Smoke-Induced Pulmonary Inflammation and Formation of Multinucleated Giant Cells}

To assess if the absence of the AhR was associated with an increase in inflammation from chronic smoke exposure, we first chose an 8-week cigarette smoke exposure, a timeframe that precedes the development of lung structural and functional alterations. There were significantly more cells in the BAL of smoke-exposed $A h r^{-/-}$mice compared to $A h r^{+/-}$ mice (Figures 1A,B). Although neutrophil numbers were significantly elevated as a consequence of an 8-week cigarette smoke-exposure, there was no significant difference in BAL neutrophils between the smoke-exposed $\mathrm{Ahr}^{-/-}$and $\mathrm{Ahr} \mathrm{r}^{\mathrm{I}-}$ mice (Figure 1C). While we also observed that cigarette smokeexposed $\mathrm{Ahr}^{-/-}$mice have significantly more macrophages (Figure 1D), there were similar levels of lymphocytes between smoke-exposed $A h r^{-/-}$and $A h r^{+/-}$mice (Figure 1E). However, there were significantly more multi-nucleated giant cells 
A BAL Cells

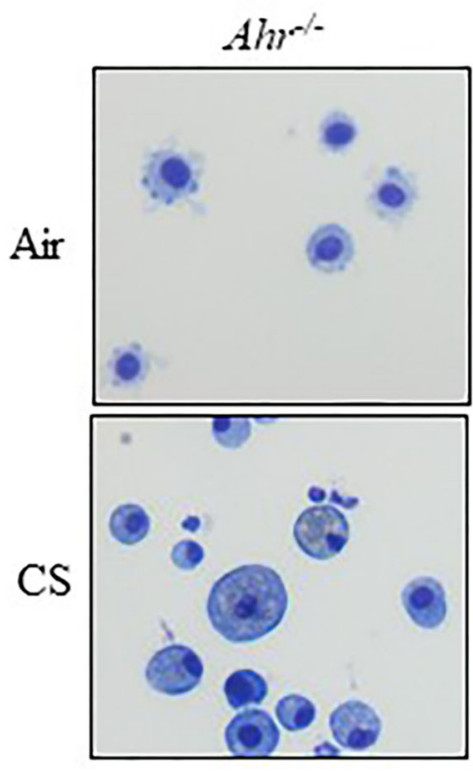

c
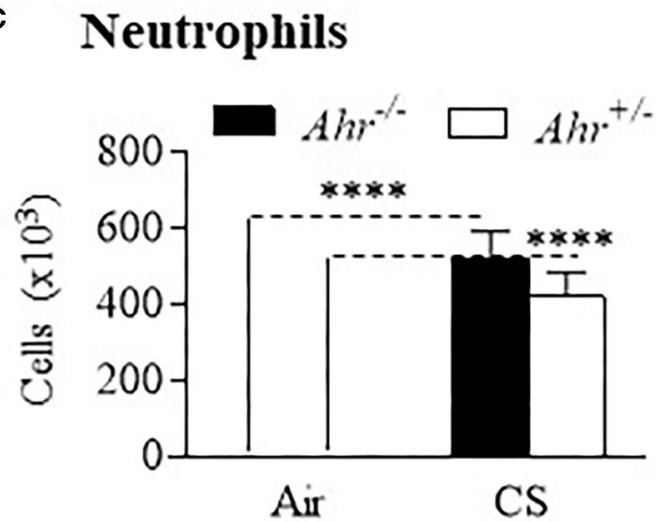

E Lymphocytes

$\square A h r^{* /-} \square A h r^{+/-}$

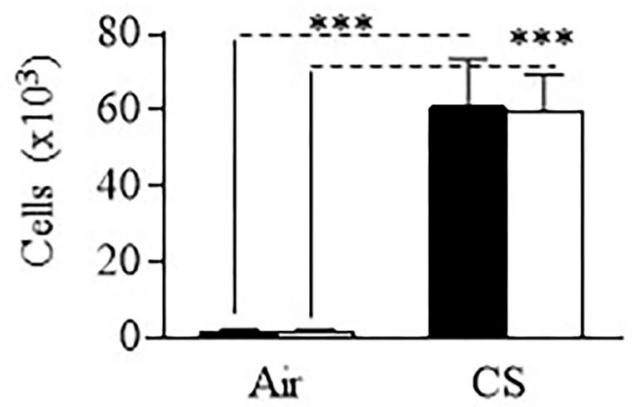

B Total Cells
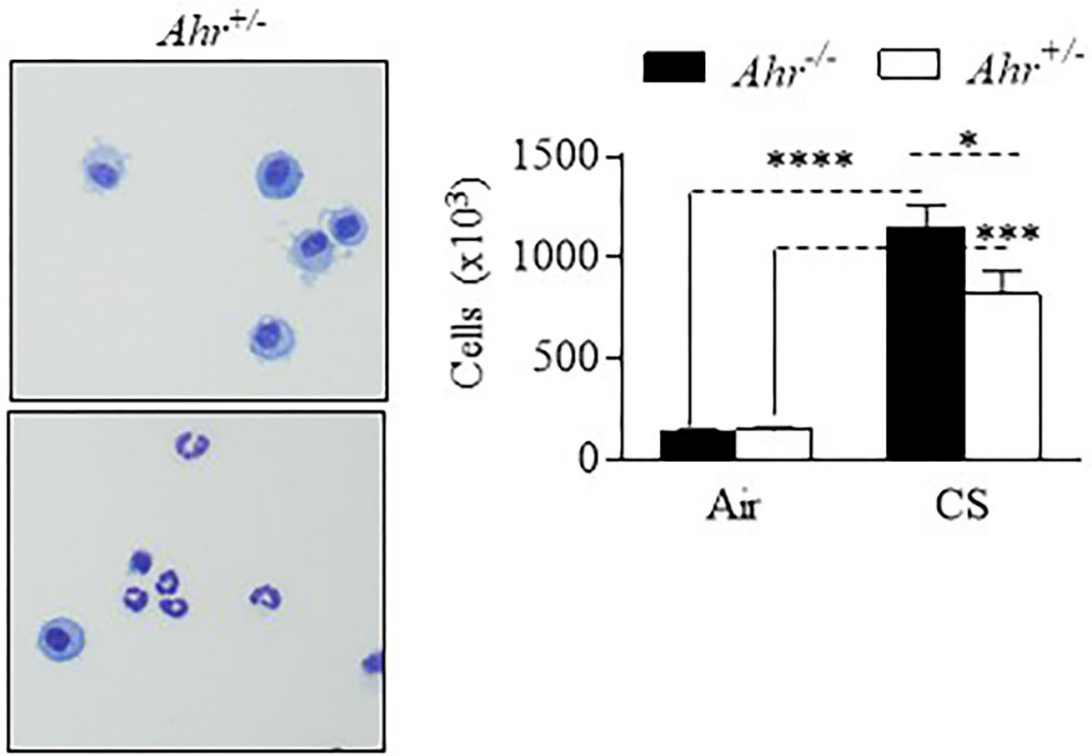

D Macrophages

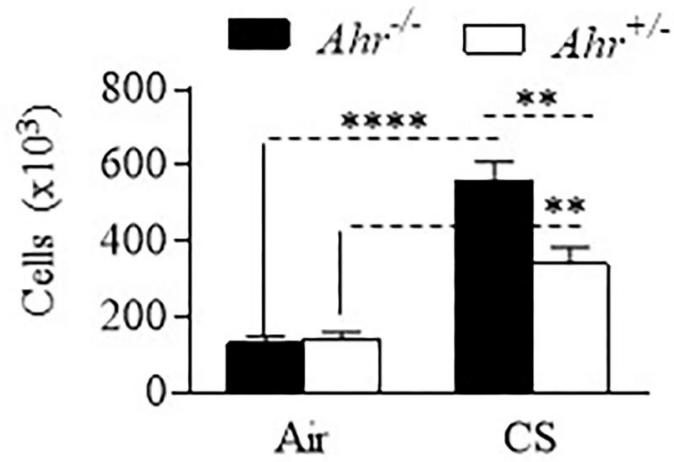

$\mathbf{F}$

MNGC

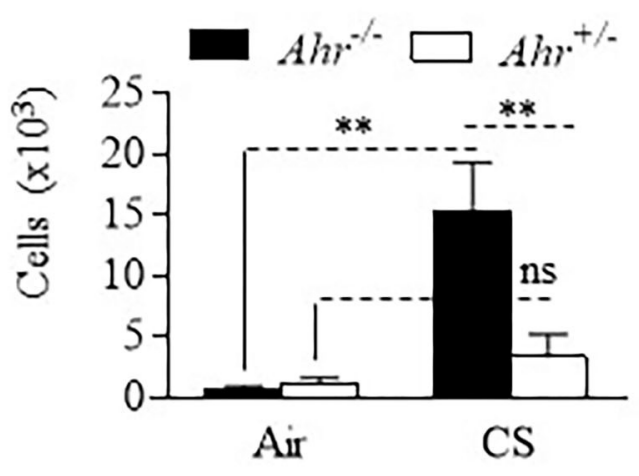

FIGURE 1 | AhR deficiency results in heightened pulmonary inflammation in response to an 8-week cigarette smoke (CS) exposure regime. (A) BAL CellsRepresentative images of cells from the BAL of $\mathrm{Ahr}^{+/-}$and $\mathrm{Ahr}^{-/-}$mice exposed to an 8-week CS regime. (B) Total Cells- There was a significant increase in 
FIGURE 1 | cellularity in response to CS $\left({ }^{* \star \star *} p<0.0001 ;{ }^{* \star *} p<0.001\right.$ compared to air-only exposure). There were significantly more BAL cells in CS-exposed $A h r^{-/-}$ mice $\left({ }^{\star} p<0.05\right.$ compared to CS-exposed Ahr ${ }^{+/-}$mice). (C) Neutrophils- CS induced a significant increase in BAL neutrophils in both $A h r^{+/-}$and $A h r^{-/-}$mice ${ }^{(\star \star \star *} p$ $<0.0001)$. (D) Macrophages- CS increased the number of macrophages in Ahr ${ }^{+/-}$and $A h r^{-/-}$mice $\left(^{\star \star \star *} p<0.0001\right)$; macrophages were also significantly higher in CS-exposed $A h r^{-/-}$mice $\left({ }^{* \star} p<0.05\right)$; (E) Lymphocytes- There was a significant increase in lymphocytes in response to CS $\left({ }^{\star \star *} p<0.001\right.$ compared to air controls. (F) MNGC-MNGCs were significantly increased in CS-exposed Ahr ${ }^{-1-}$ mice compared to both air-exposed $A h r^{-1-}$ mice $\left({ }^{* *} p<0.01\right)$ as well as CS-exposed Ahr $r^{+/-}$ mice $\left({ }^{\star *} p<0.01\right)$. Results are expressed as mean \pm SEM, $n=4-5$ mice per group; 2-way ANOVA followed by the Neuman-Keuls multiple comparisons test.

\section{A Neutrophil}
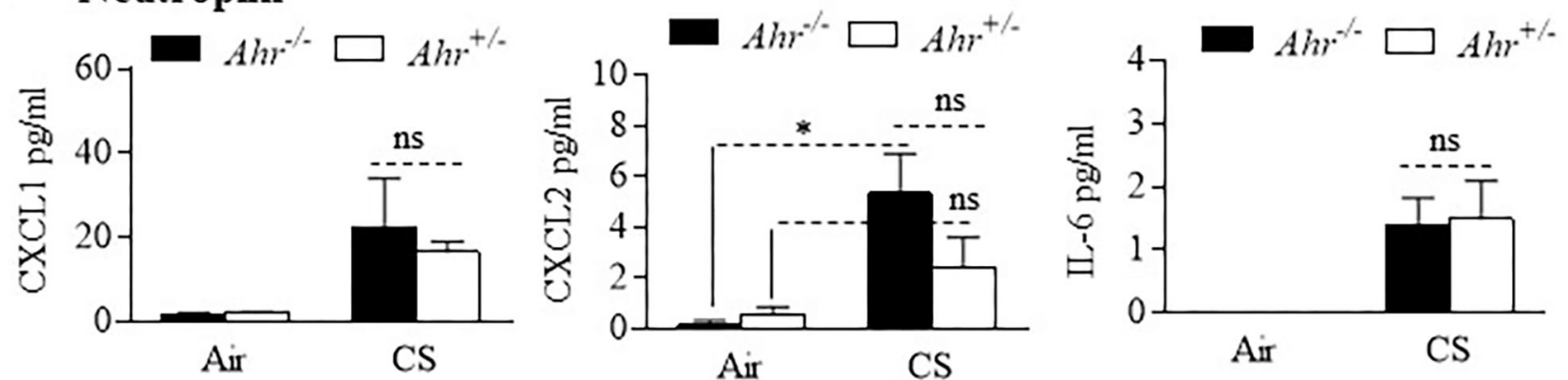

\section{B Monocyte/macrophage}
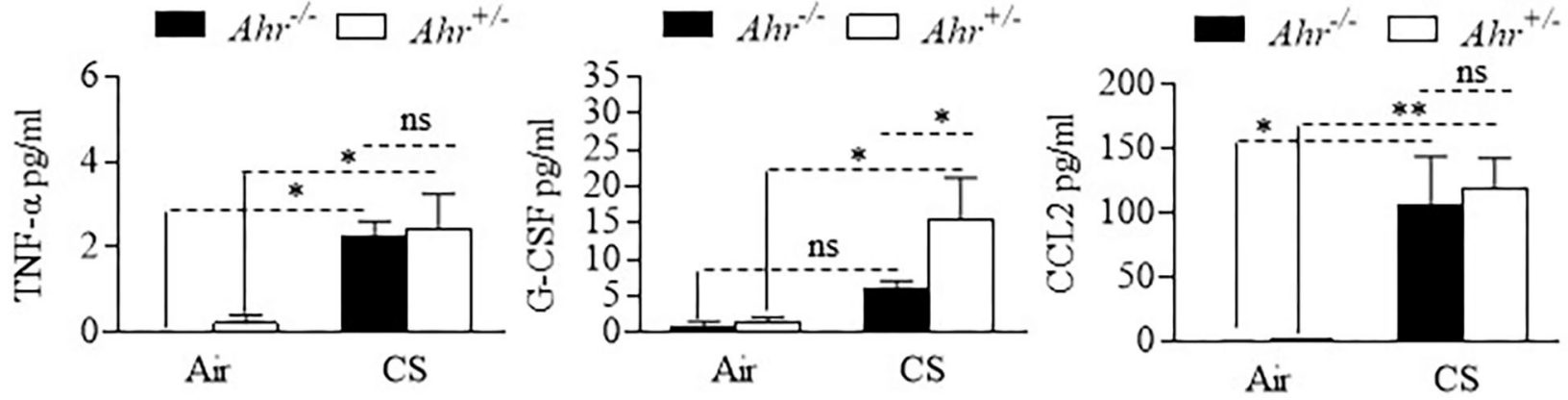

\section{c Lymphocytes}

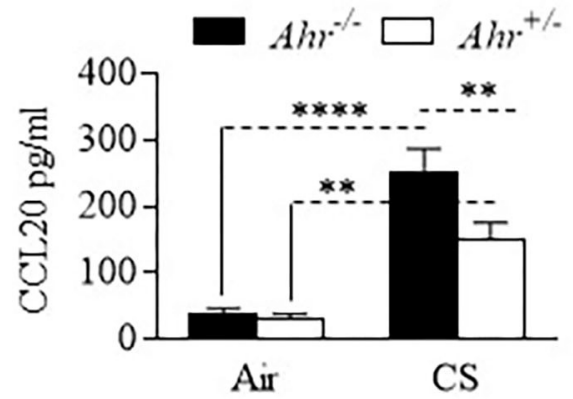

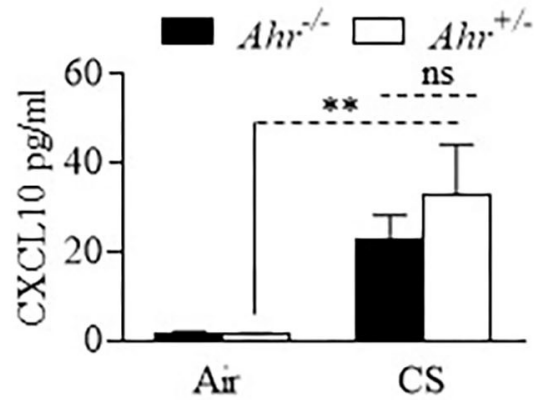

D Th17 response

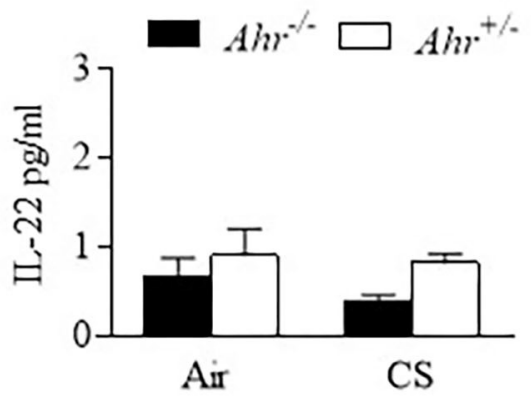

FIGURE 2 | Differential analysis of BAL cytokines is similar between smoke-exposed Ahr $r^{-/-}$and $A h r^{-1-}$ mice. Ahr ${ }^{+/-}$and Ahr ${ }^{-/-}$mice were exposed to an 8-week CS regime and cytokines analyzed in the BAL fluid by multiplex analysis. (A) Neutrophils- there was an overall increase in the levels of CXCL1, CXCL2, IL-6, TNF- $\alpha$, and G-CSF after 8 weeks of cigarette smoke exposure; except for G-CSF, there was little difference between smoke-exposed $A h r^{+/-}$and $A h r^{-/-}$mice ${ }^{*} p<0.05$; ns $=$ not significant). (B) Monocyte/macrophage- although CS increased BAL levels, there was no difference in CCL2 between Ahr ${ }^{+/-}$and Ahr ${ }^{-/-}$mice (** $\left.p<0.01\right)$. (C) Lymphocytes- there was a significant increase in CCL20 in response to CS; there was significantly more CCL20 in the BAL of smoke-exposed $A h r /-$ mice $\left({ }^{*} p<\right.$ $\left.0.01 ;{ }^{* \star \star \star} p<0.0001\right)$. (D) Th17 response- IL-22 was unaffected by smoke exposure or AhR expression. Results are shown as means \pm SEM $(n=4-5$ mice per group); 2-way ANOVA followed by the Neuman-Keuls multiple comparisons test. 


\section{A Representative BAL}
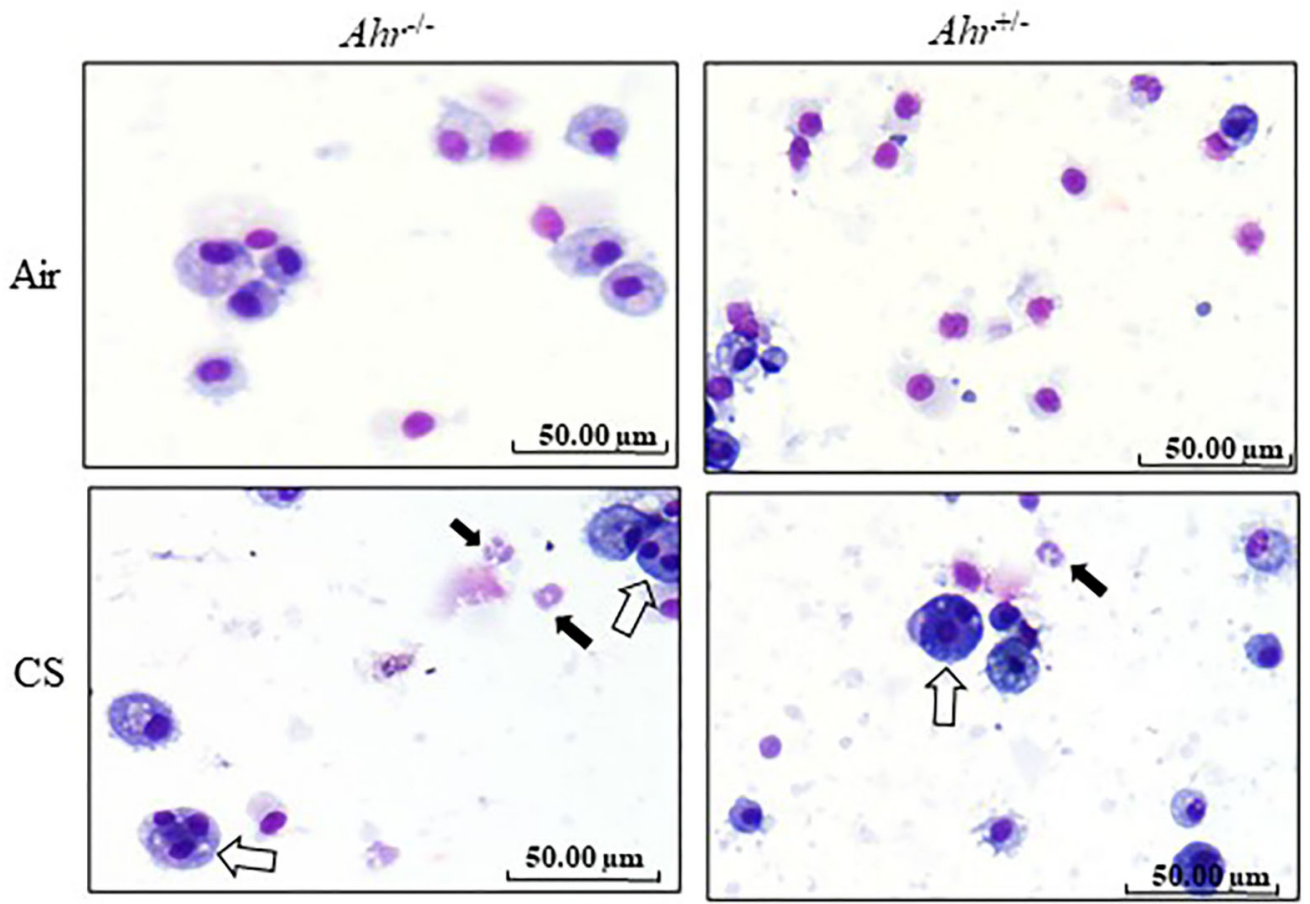

B

Total cells

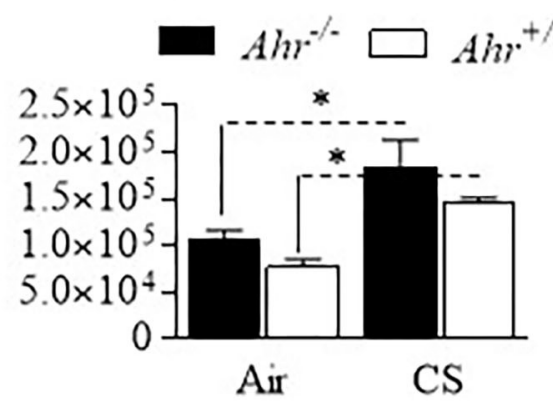

D

Macrophages

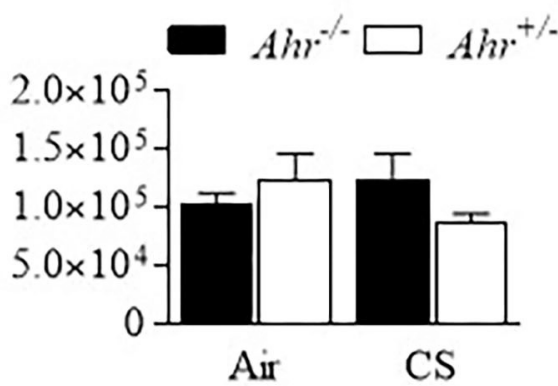

c Neutrophils
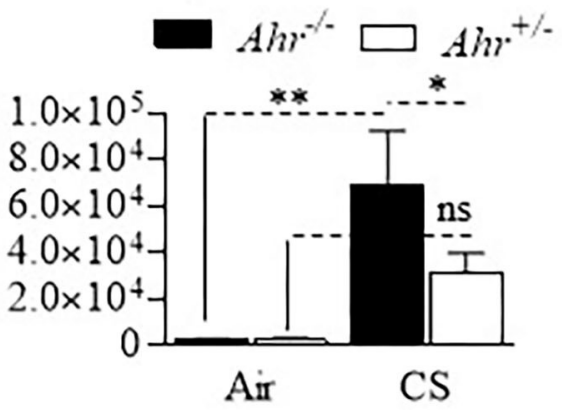

E

MNGC
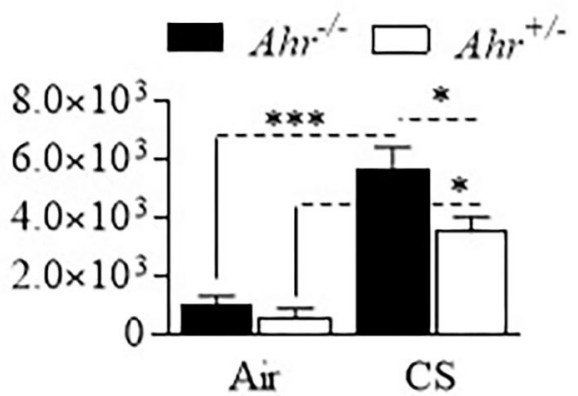

FIGURE 3 | Exposure to CS for 4 months causes heightened pulmonary inflammation characterized by the continued presence of MNGC. (A) BAL CellsRepresentative images of cells from the BAL of $\mathrm{Ahr}^{+/-}$and $\mathrm{Ahr}^{-/-}$mice exposed to CS for 4 months. Note the presence of neutrophils (black arrows) and 
FIGURE 3 | MNGCs (open arrows). (B) Total Cells- There was a significant increase in cellularity in response to CS ( ${ }^{*} p<0.05$ compared to air-only exposure). (C) Neutrophils- CS induced an increase in BAL neutrophils in $\mathrm{Ahr}^{+/-}$and $\mathrm{Ahr^{-1- }}$ mice $\left({ }^{\star *} \mathrm{p}<0.0001\right)$ that was higher in Ahr ${ }^{-/-}$mice. (D) Macrophages- There was no change in the number of macrophages in response to CS. (E) MNGC- MNGCs were significantly increased in CS-exposed Ahr ${ }^{-1-}$ mice compared to both air-exposed $A h r^{-1-}$ mice $\left({ }^{* \star *} p<0.001\right)$ as well as CS-exposed Ahrt/- mice $\left({ }^{*} p<0.01\right)$. Results are expressed as mean \pm SEM, $n=9-11$ mice per group; 2 -way ANOVA followed by the Neuman-Keuls multiple comparisons test.

(MNGCs) in the BAL of $A h r^{-/-}$mice exposed to cigarette smoke for 8 weeks (Figure 1F).

We also evaluated different types of cytokines in the BAL, including interleukins, tumor necrosis factor (TNF), chemokines and colony stimulating factors (CSF) after an 8-week cigarette smoke exposure. Although BAL cytokines were generally increased by cigarette smoke, there was little difference between $A h r^{+/-}$and $A h r^{-/-}$ mice (Figure 2). These included cytokines associated with neutrophil recruitment such as CXCL1, CXCL2 and IL-6 (Figure 2A). G-CSF was significantly higher in smokeexposed $A h r^{+/-}$mice. Of the cytokines analyzed, only CCL20 was significantly higher in smoke-exposed $\mathrm{Ahr}^{-/-}$ mice (Figure 2C). There was no increase in IL-22 with cigarette smoke (Figure 2D).

The heightened inflammatory response persisted in the Ahr ${ }^{-/}$mice through 4 months of daily cigarette smoke exposure (Figure 3A). Although there was no significant change in the total number of cells (Figure 3B), there were higher number of neutrophils in $\mathrm{Ahr}^{-/-}$mice exposed to cigarette smoke for 4 months (Figure 3C). While there was no difference in the number of macrophages between any of the treatment conditions (Figure 3D), there was a significant increase in the number of MNGCs in smoke-exposed $A h r^{+/}$and $A h r^{-/-}$mice (Figure 3E). Moreover, there were also significantly more MNGCs in the smoke-exposed $A h r^{-/-}$mice compared to $\mathrm{Ahr} \mathrm{H}^{+/-}$mice exposed to a 4-month smoke regime (Figure 3E). These data show for the first time that the AhR prevents the formations of MNGCs, an enigmatic cell type linked to several pathologies.

Finally, we evaluated BAL cytokines after the 4 month exposure regime and included additional cytokines to more comprehensively profile cytokine changes induced by smoke that may also be controlled by the AhR. Of the 31 cytokines analyzed, 8 were increased with chronic 4 -month cigarette smoke exposure, including those associated with recruitment of neutrophils (Figure 4A) and monocyte/macrophages (Figure 4B) but not lymphocytes (Figure 4C). However, there was no difference in the levels of these cytokines based on AhR expression. Cytokines also evaluated but whose levels in the BAL were unaffected by cigarette smoke included eotaxin, IFN- $\gamma$, IL- $1 \alpha$, IL-1 $\beta$, IL-2, IL-3, Il-4, IL-7, Il-9, IL-12p40, IL-12p70, IL-10, IL13, IP-10, LIF, LIX, M-CSF, RANTES, and VEGF (data not shown). Thus, the AhR continues to emerge as an important protein involved in protecting the lungs against the deleterious effects of cigarette smoke, a prevalent respiratory toxicant that still causes significant morbidity and mortality around the world.

\section{DISCUSSION}

Although the AhR has been studied for decades, its physiological role has been elusive. Herein, we extend our previous finds to show the importance of $\mathrm{AhR}$ in the suppression of chronic cigarette smoke-induced pulmonary inflammation. We utilized two different exposure times- 8 weeks and 4 months- to mimic the scenario faced by people who smoke for decades. While cigarette smoke induces neutrophilia in the airways after $\sim 5$ days in C57BL/ 6 mice, increases in macrophage numbers become evident after 2 weeks and progressively increase through 6 months (D'hulst et al., 2005). We have previously reported that the Ahr-deficient mice exhibit significantly greater neutrophilia following acute smoke exposure (Thatcher et al., 2007), but whether the AhR can also protect against chronic exposure is not known. Herein, we report that chronic smoke-exposed Ahrdeficient mice exhibit an exaggerated inflammatory response typified by an initial increase in macrophages (8-weeks) and continued the presence of MNGCs (at 8-weeks and 4 months).

Macrophages undergo fusion with other macrophages to form MNGCs, a hallmark of chronic inflammation observed in tissues that incur persistent insults from foreign particles (Petersen and Smith, 2013), which is why they are often referred to as foreign body giant cells (FBGCs) (Brooks et al., 2019). FBGCs often form as a result of implanted material and are associated with their degradation. In addition, MNGCs are found in tuberculous where they may promote the inflammatory process. The role of MNGCs in tuberculous infection remains controversial, in that these cells may limit spread of the infection or promote tissue destruction (Losslein et al., 2021). Of relevance to our findings, MNGCs are also important sources of reactive oxygen species (Quinn and Schepetkin, 2009) and matrix metalloproteinase9 (MMP-9) (Zhu et al., 2007) that may damage the lungs. MNGCs have recently been identified in the BAL of COVID19 patients (Canini et al., 2021). However, identify of the precursor cells leading to the formation of MNGCs is unclear. Although macrophages and monocyte progenitors can give rise to MNGCs (Losslein et al., 2021), respiratory epithelial cells may give rise to MNGCs under certain conditions, such as viral infection (Lin et al., 2021). Although the physiological significance of MNGCs in chronic inflammation is not wellunderstood, our findings provide evidence for a protective role for the AhR in mitigating their formation and possible disease development.

Overall, these results continue to support a homeostatic role for the AhR in the maintenance of lung health (Guerrina et al., 2018). It also provides sufficient evidence to speculate that the AhR may lessen the susceptibility to COPD pathogenesis by attenuating chronic smoke-induced pulmonary damage 


\section{A Neutrophil}
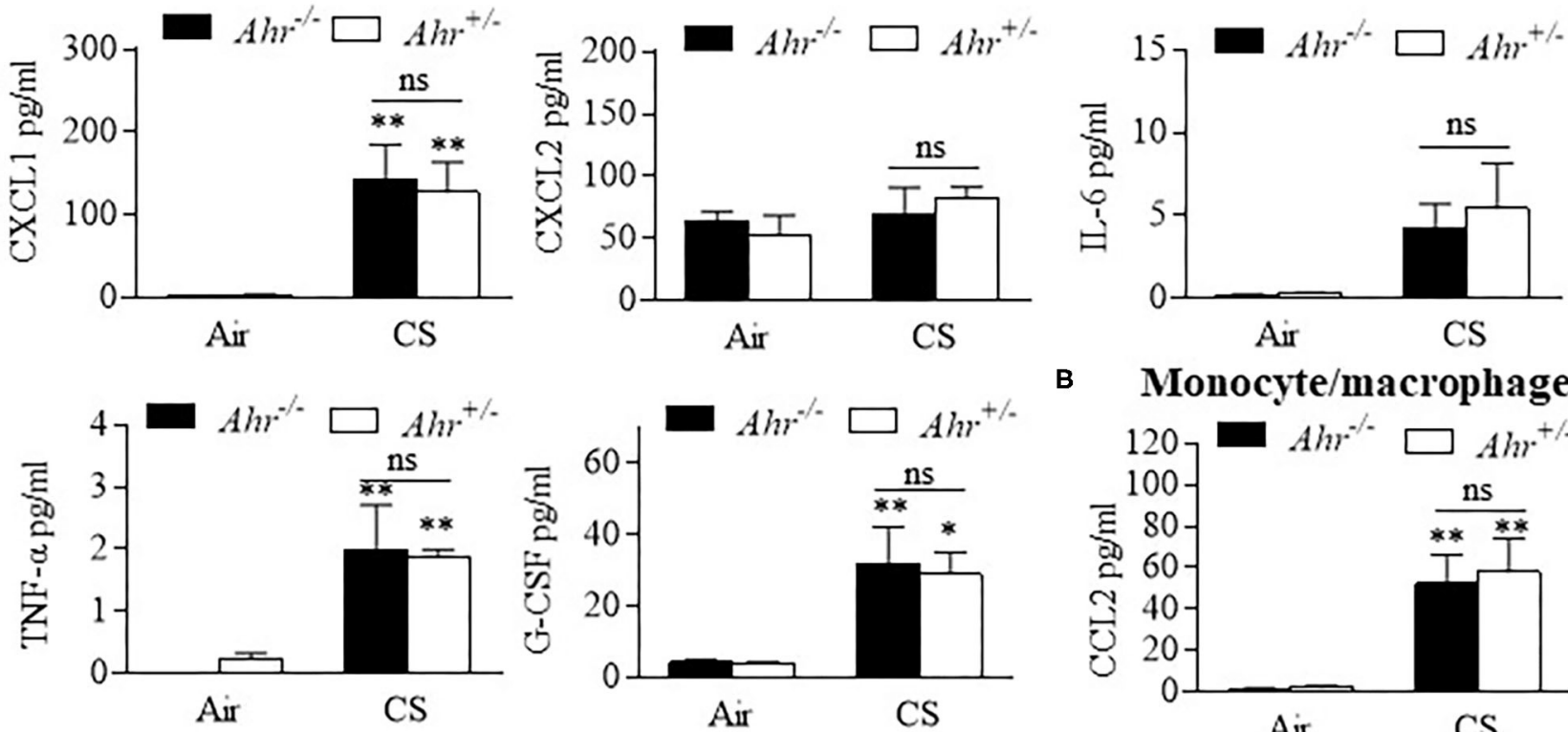

B Monocyte/macrophage
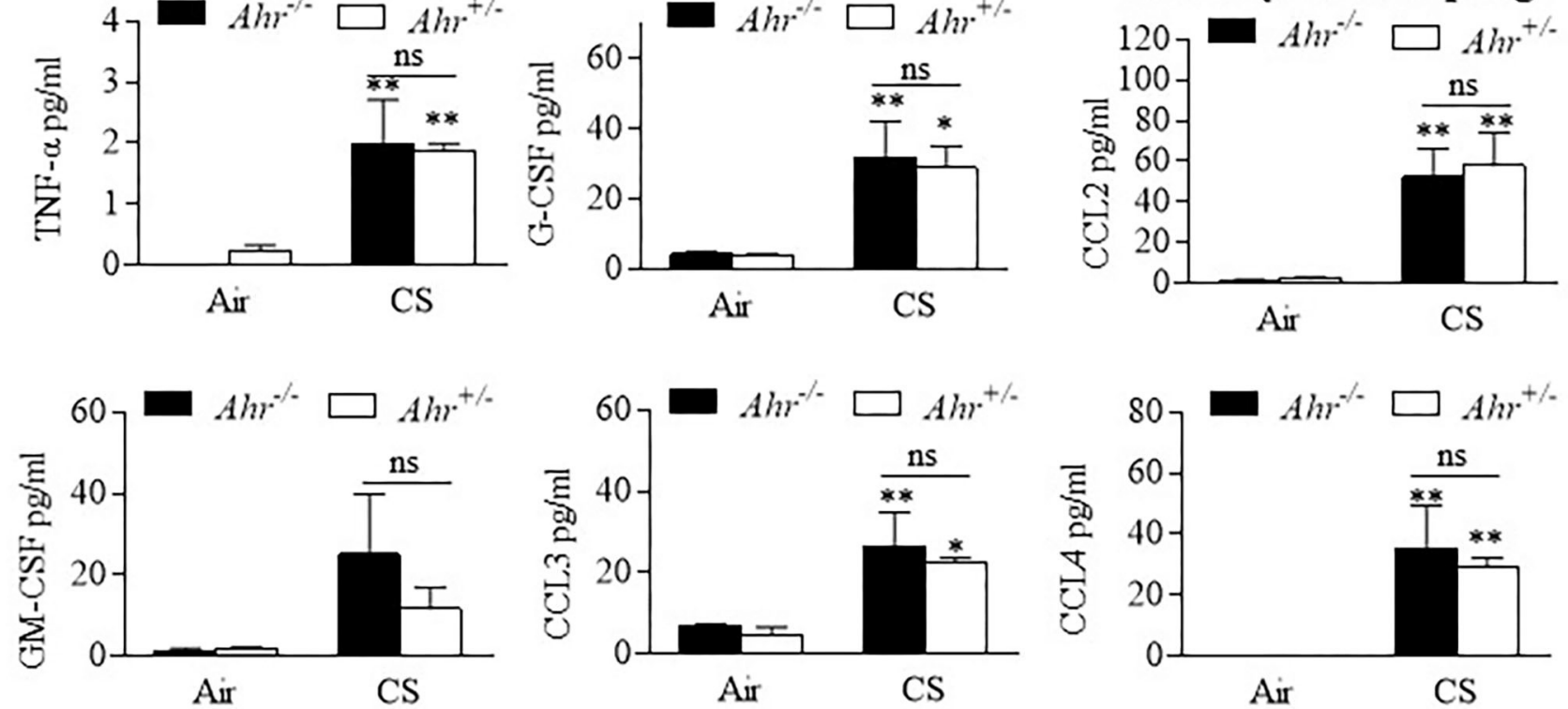

\section{c Lymphocytes}
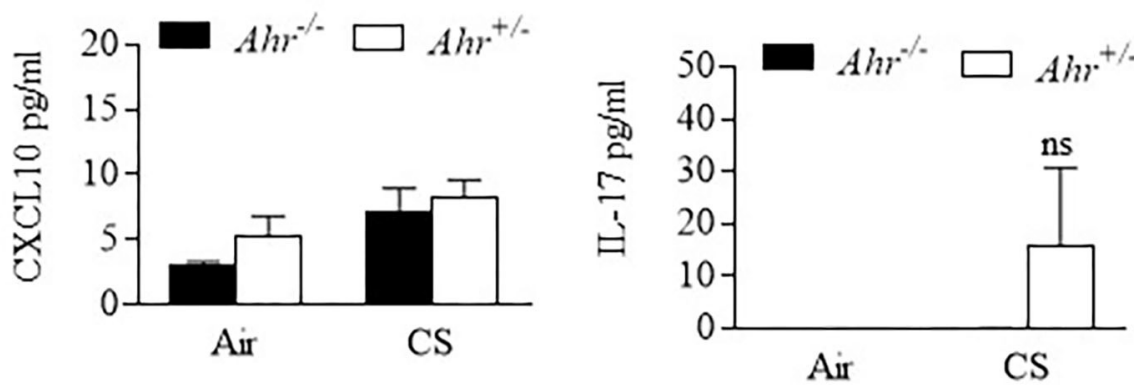

FIGURE 4 | BAL cytokines are similar between chronic 4-month cigarette smoke-exposed Ahr'/- and Ahr ${ }^{-/-}$mice. Ahr ${ }^{+/-}$and $A h r^{-/-}$mice were exposed to a 4-month CS regime and cytokines analyzed in the BAL fluid by multiplex analysis. (A) Neutrophils- there was an overall increase in the levels of CXCL1, IL-6, TNF- $\alpha$ and G-CSF after 4 months of CS exposure $\left({ }^{\star} p<0.05,{ }^{\star \star} p<0.01\right.$ compared to corresponding air-control); there was no significant difference (ns) between smoke-exposed $\mathrm{Ahr}^{+/-}$and $\mathrm{Ahr}{ }^{-/-}$mice. (B) Monocyte/macrophage- although CS generally increased BAL levels of CCL2, CCL3, and CCL4, there was no significant difference between $\mathrm{Ahr}^{+/-}$and $\mathrm{Ahr} \mathrm{r}^{-/-}$mice. (C) Lymphocytes- there was no significant change in CXCL10 or IL-17 in response to CS. Results are shown as means \pm SEM ( $n=4-5$ mice per group); 2-way ANOVA followed by the Neuman-Keuls multiple comparisons test.

by controlling the formation of MNGCs. Cellular pathways leading to the formation of MNGCs remain poorly understood. Therefore, these results provide evidence for the first time that the AhR is a biological pathway that reduces their formation in the lungs. Although we speculate that the ability of the AhR to prevent formation of MNGCs contributes to suppression of the 
emphysema-like phenotype (Guerrina et al., 2021), a limitation of our study is that we did not directly address whether MNGCs contribute to smoke-induced lung damage. We also did not evaluate how the AhR controls their formation or identify the cellular precursor(s). Given that AhR is expressed in multiple cell types, including structural and hematopoietic cells, and that AhR suppresses the influx of numerous immune cells to the lungs from both short and prolonged smoke exposures (Thatcher et al., 2007; de Souza et al., 2014; Rico de Souza et al., 2021), it is likely the cumulative effect of the AhR that ultimately prevent lung damage from cigarette smoke. Nonetheless, these results set the stage for further mechanistic studies aimed at addressing the contribution of MNGCs to the pathogenesis of diseases like COPD. Although smoking cessation remains the most effective strategy for slowing progression and reducing mortality (Tashkin, 2015), quitting smoking does not eliminate the risk of disease development. Continued investigation into the mechanistic basis by which the AhR controls inflammation may uncover new therapeutic targets to combat prevalent lungs diseases in both current and former smokers around the world.

\section{DATA AVAILABILITY STATEMENT}

The raw data supporting the conclusions of this article will be made available by the authors, without undue reservation.

\section{REFERENCES}

Abdullah, A., Maged, M., Hairul-Islam, M. I., Osama, I. A., Maha, H., Manal, A., et al. (2019). Activation of aryl hydrocarbon receptor signaling by a novel agonist ameliorates autoimmune encephalomyelitis. PLoS ONE 14:e0215981. doi: 10.1371 /journal.pone.0215981

Abel, J., and Haarmann-Stemmann, T. (2010). An introduction to the molecular basics of aryl hydrocarbon receptor biology. Biol. Chem. 391, 1235-1248. doi: $10.1515 /$ bc. 2010.128

Baglole, C. J., Maggirwar, S. B., Gasiewicz, T. A., Thatcher, T. H., Phipps, R. P., and Sime, P. J. (2008). The aryl hydrocarbon receptor attenuates tobacco smokeinduced cyclooxygenase- 2 and prostaglandin production in lung fibroblasts through regulation of the NF-kappaB family member RelB. J. Biol. Chem. 283, 28944-28957. doi: 10.1074/jbc.M800685200

Bock, K. W. (1994). Aryl hydrocarbon or dioxin receptor: biologic and toxic responses. Rev. Physiol. Biochem. Pharmacol. 125, 1-42. doi: 10.1007/BFb0030908

Brooks, P. J., Glogauer, M., and Mcculloch, C. A. (2019). An overview of the derivation and function of multinucleated giant cells and their role in pathologic processes. Am. J. Pathol. 189, 1145-1158. doi: 10.1016/j.ajpath.2019.02.006

Canini, V., Bono, F., Calzavacca, P., Capitoli, G., Foti, G., Fraggetta, F., et al. (2021). Cytopathology of bronchoalveolar lavages in COVID-19 pneumonia: a pilot study. Cancer Cytopathol. doi: 10.1002/cncy.22422. [Epub ahead of print].

Chang, Y. D., Li, C. H., Tsai, C. H., Cheng, Y. W., Kang, J. J., and Lee, C. C. (2020). Aryl hydrocarbon receptor deficiency enhanced airway inflammation and remodeling in a murine chronic asthma model. FASEB J. 34, 15300-15313. doi: 10.1096/fj.202001529R

de Souza, A. R., Zago, M., Eidelman, D. H., Hamid, Q., and Baglole, C. J. (2014). Aryl hydrocarbon receptor (AhR) attenuation of subchronic cigarette smokeinduced pulmonary neutrophilia is associated with retention of nuclear RelB and suppression of intercellular adhesion molecule-1 (ICAM-1). Toxicol. Sci. 140, 204-223. doi: 10.1093/toxsci/kfu068

\section{ETHICS STATEMENT}

The animal study was reviewed and approved by all animal procedures were approved by the McGill University Animal Care Committee (Protocol Number: 5933) and were carried out in accordance with the Canadian Council on Animal Care.

\section{AUTHOR CONTRIBUTIONS}

NG, HT, and CB: data curation and analysis and project administration. CB: funding acquisition and supervision. NG and HT: investigation and methodology. NG, HT, CB, and DE: intellectual contributions, manuscript writing, review, and editing. All authors contributed to the article and approved the submitted version.

\section{FUNDING}

This work was supported by the Canada Foundation for Innovation (CFI), the Canadian Institutes for Health Research Project Grants (168836 and 162273) and the Natural Sciences and Engineering Research Council of Canada (NSERC). CB was supported by a salary award from the Fonds de recherche du Quebec-Sante (FRQ-S). HT was supported by a Réseau de recherche en santé réspiratoire du Québec (RSR) Scholarship and a Meakins-Christie Laboratories Collaborative Research Award.

D'hulst, A., I., Vermaelen, K. Y., Brusselle, G. G., Joos, G. F., and Pauwels, R. A. (2005). Time course of cigarette smoke-induced pulmonary inflammation in mice. Eur. Respir. J. 26, 204-213. doi: 10.1183/09031936.05.00 095204

Di Meglio, P., Duarte, J. H., Ahlfors, H., Owens, N. D., Li, Y., Villanova, F., et al. (2014). Activation of the aryl hydrocarbon receptor dampens the severity of inflammatory skin conditions. Immunity 40, 989-1001. doi: 10.1016/j.immuni.2014.04.019

Dutta, S., and Sengupta, P. (2016). Men and mice: relating their ages. Life Sci. 152, 244-248. doi: 10.1016/j.lfs.2015.10.025

Esser, C., and Rannug, A. (2015). The aryl hydrocarbon receptor in barrier organ physiology, immunology, and toxicology. Pharmacol. Rev. 67, 259-279. doi: $10.1124 /$ pr.114.009001

Fernandez-Salguero, P. M., Hilbert, D. M., Rudikoff, S., Ward, J. M., and Gonzalez, F. J. (1996). Aryl-hydrocarbon receptor-deficient mice are resistant to 2,3,7,8tetrachlorodibenzo-p-dioxin-induced toxicity. Toxicol. Appl. Pharmacol. 140, 173-179. doi: 10.1006/taap.1996.0210

Guerrina, N., Traboulsi, H., Eidelman, D. H., and Baglole, C. J. (2018). The aryl hydrocarbon receptor and the maintenance of lung health. Int. J. Mol. Sci. 19:3882. doi: 10.3390/ijms19123882

Guerrina, N., Traboulsi, H., Rico De Souza, A., Bosse, Y., Thatcher, T. H., Robichaud, A., et al. (2021). Aryl hydrocarbon receptor deficiency causes the development of chronic obstructive pulmonary disease through the integration of multiple pathogenic mechanisms. FASEB J. 35:e21376. doi: 10.1096/fj.202002350R

Huang, J., Cai, X., Ou, Y., Fan, L., Zhou, Y., and Wang, Y. (2019). Protective roles of FICZ and aryl hydrocarbon receptor axis on alveolar bone loss and inflammation in experimental periodontitis. J. Clin. Periodontol. 46, 882-893. doi: $10.1111 /$ jcpe. 13166

Lin, W. W., Tsay, A. J., Lalime, E. N., Pekosz, A., and Griffin, D. E. (2021). Primary differentiated respiratory epithelial cells respond to apical measles virus infection by shedding multinucleated giant cells. Proc. Natl. Acad. Sci. U.S.A. 118:e2013264118. doi: 10.1073/pnas.2013264118 
Losslein, A. K., Lohrmann, F., Scheuermann, L., Gharun, K., Neuber, J., Kolter, J., et al. (2021). Monocyte progenitors give rise to multinucleated giant cells. Nat. Commun. 12:2027. doi: 10.1038/s41467-021-22103-5

Mimura, J., Yamashita, K., Nakamura, K., Morita, M., Takagi, T. N., Nakao, K., et al. (1997). Loss of teratogenic response to 2,3,7,8-tetrachlorodibenzo-p-dioxin (TCDD) in mice lacking the Ah (dioxin) receptor. Genes Cells 2, 645-654. doi: 10.1046/j.1365-2443.1997.1490345.x

Nehmar, R., Fauconnier, L., Alves-Filho, J., Togbe, D., Decauwer, A., Bahram, S., et al. (2021). Aryl hydrocarbon receptor (Ahr)-dependent Il-22 expression by type 3 innate lymphoid cells control of acute joint inflammation. J. Cell Mol. Med. 25, 4721-4731. doi: 10.1111/jc mm. 16433

Nukaya, M., Moran, S., and Bradfield, C. A. (2009). The role of the dioxinresponsive element cluster between the Cypla1 and Cypla2 loci in aryl hydrocarbon receptor biology. Proc. Natl. Acad. Sci. U.S.A. 106, 4923-4928. doi: 10.1073/pnas.0809613106

Petersen, H. J., and Smith, A. M. (2013). The role of the innate immune system in granulomatous disorders. Front. Immunol. 4:120. doi: 10.3389/fimmu.2013.00120

Quinn, M. T., and Schepetkin, I. A. (2009). Role of NADPH oxidase in formation and function of multinucleated giant cells. J. Innate Immun. 1, 509-526. doi: $10.1159 / 000228158$

Quintana, F. J. (2013). The aryl hydrocarbon receptor: a molecular pathway for the environmental control of the immune response. Immunology 138, 183-189. doi: 10.1111/imm.12046

Rico de Souza, A., Traboulsi, H., Wang, X., Fritz, J. H., Eidelman, D. H., and Baglole, C. J. (2021). The Aryl hydrocarbon receptor attenuates acute cigarette smoke-induced airway neutrophilia independent of the dioxin response element. Front. Immunol. 12:630427. doi: 10.3389/fimmu.2021. 630427

Riemschneider, S., Hoffmann, M., Slanina, U., Weber, K., Hauschildt, S., and Lehmann, J. (2021). Indol-3-carbinol and quercetin ameliorate chronic DSS-induced colitis in C57BL/6 mice by ahr-mediated antiinflammatory mechanisms. Int. J. Environ. Res. Public Health 18:2262. doi: 10.3390/ijerph18052262
Rosser, E. C., Piper, C. J. M., Matei, D. E., Blair, P. A., Rendeiro, A. F., Orford, M., et al. (2020). Microbiota-derived metabolites suppress arthritis by amplifying Aryl-hydrocarbon receptor activation in regulatory B cells. Cell Metab. 31, 837-851.e810. doi: 10.1016/j.cmet.2020.03.003

Tashkin, D. P. (2015). Smoking cessation in chronic obstructive pulmonary disease. Semin. Respir. Crit. Care Med. 36, 491-507. doi: 10.1055/s-0035-1555610

Thatcher, T. H., Maggirwar, S. B., Baglole, C. J., Lakatos, H. F., Gasiewicz, T. A., Phipps, R. P., et al. (2007). Aryl hydrocarbon receptor-deficient mice develop heightened inflammatory responses to cigarette smoke and endotoxin associated with rapid loss of the nuclear factor-kappaB component RelB. Am. J. Pathol. 170, 855-864. doi: 10.2353/ajpath.2007.060391

Williams, E. G., Mouchiroud, L., Frochaux, M., Pandey, A., Andreux, P. A., Deplancke, B., et al. (2014). An evolutionarily conserved role for the aryl hydrocarbon receptor in the regulation of movement. PLoS Genet 10:e1004673. doi: 10.1371/journal.pgen.1004673

Zago, M., Sheridan, J. A., Nair, P., Rico De Souza, A., Gallouzi, I. E., Rousseau, S. et al. (2013). Aryl hydrocarbon receptor-dependent retention of nuclear HuR suppresses cigarette smoke-induced cyclooxygenase-2 expression independent of DNA-binding. PLoS ONE 8:e74953. doi: 10.1371/journal.pone.0074953

Zhu, X. W., Price, N. M., Gilman, R. H., Recarvarren, S., and Friedland, J. S. (2007). Multinucleate giant cells release functionally unopposed matrix metalloproteinase-9 in vitro and in vivo. J. Infect. Dis. 196, 1076-1079. doi: $10.1086 / 521030$

Conflict of Interest: The authors declare that the research was conducted in the absence of any commercial or financial relationships that could be construed as a potential conflict of interest.

Copyright (C) 2021 Guerrina, Traboulsi, Eidelman and Baglole. This is an open-access article distributed under the terms of the Creative Commons Attribution License (CC $B Y)$. The use, distribution or reproduction in other forums is permitted, provided the original author(s) and the copyright owner(s) are credited and that the original publication in this journal is cited, in accordance with accepted academic practice. No use, distribution or reproduction is permitted which does not comply with these terms. 